\title{
Effects of STEM Inquiry Method on Learning Attitude and Creativity
}

\author{
Kieranna Chen ${ }^{1}$, Chenin Chen ${ }^{2 *}$ \\ ${ }^{1}$ Sasin Graduate Institute of Business Administration of Chulalongkorn University, Phayathai Road, Pathumwan, Bangkok, \\ THAILAND \\ ${ }^{2}$ Chulalongkorn Business School, Chulalongkorn University, Phayathai Road, Pathumwan, Bangkok, THAILAND
}

Received 20 June 2021 - Accepted 22 August 2021

\begin{abstract}
The innovative education trend is gradually developed on/off campus in past years. The constant integration of digital technology with education generating the new-style education model redefines the integrated activity and information technology curricula at schools. Creative thinking aims to cultivate students combining various situations (e.g., scientific situation, industrial situation, living situation) with creative design and developing original research and problem solving with specific engineering goals.

Taking college students in Bangkok, Thailand, as the research object, total 316 students are preceded the 16-week (3 hours per week for total 48 hours) STEM inquiry method experimental research. The research results are summarized as below. 1. STEM inquiry method cultivates students' personal scientific activity and inquiry ability without restricting the ideas, but guides students to experience the complete learning process. 2. STEM education, with integrated instruction, cultivates students learning knowledge and skills for the application to real life. During students' learning, the integration of subject knowledge, life experience, and learner-centered is emphasized. 3. Taking the curriculum design principle of STEM inquiry method, i.e. students' interested issues, into the consideration of curriculum design and combining several relevant curriculum fields for integrated instruction, the planned self-directed learning activities and opportunities could assist students in applying the learned knowledge to solve problems in real life so as to enhance students' creative thinking ability. According to the results to propose suggestions, it is expected to help students learn complete knowledge and, more importantly, present critical thinking and problem solving abilities.
\end{abstract}

Keywords: STEM teaching, inquiry method, learning attitude, creativity

\section{INTRODUCTION}

Education aims to assist people in applying knowledge to have better quality of life. Most people would not apply knowledge learned at schools to daily life, nor combine daily life experiences with knowledge learned at schools. In other words, they could not apply the learned knowledge among different subjects. To achieve the coherent and integrated learning theme, the combination with life situation allows students comprehending learning content and further integrating with real application, problem solving, and continuous innovation to achieve the effectiveness of lifelong learning. The learning point would be the ability and knowledge-oriented learning.

The innovative education trend is gradually developed on/off campus in past years. Regarding digital technology as the education content and tactic is a new-style education model with the constant integration of digital technology and education to redefine the integrated activity curricula and information technology curricula at schools. The innovative education content would bear dimensions of innovation, production, and wisdom to innovatively perform on creative thinking and transboundary thinking. Creative thinking aims to cultivate students to combine various situations (e.g., scientific situation, industrial situation,

(C) 2021 by the authors; licensee Modestum. This article is an open access article distributed under the terms and conditions of the Creative Commons Attribution License (http://creativecommons.org/licenses/by/4.0/).

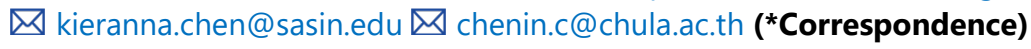




\section{Contribution to the literature}

- STEM inquiry method aims to have students cultivate personal scientific activity and inquiry ability through the participation process.

- STEM education, with integrated instruction, cultivates students to learn knowledge and skills and apply to real life.

- The characteristics of STEM inquiry method show the course content containing problems in students' life or social issues to combine with students' life experience and induce students' learning interests.

living situation) with creative design and develop original research and problem solving with specific engineering goals. Trial-and-error learning model or manual training model are no longer suitable for technology-based learning; instead, it is necessary to integrate and design/produce product related mathematical and scientific principles as the reference for modification or innovation. It becomes an inevitably emphasized issue in current education. Apparently, technology should be reinforced and emphasized. In the future world, knowledge itself is no longer valuable; the objective of education promotion should be advanced from simple "knowledge delivery" to students' "applying what is learned". The promotion of science, technology, engineering, and mathematics (STEM) education allows future children presenting knowledge and problem-solving ability, understanding the spirit of positivism, and having the thought of integrating distinct information into available resources. For this reason, the effect of STEM inquiry method on learning attitude and creativity is discussed in this study, expecting to help students learn complete knowledge and, more importantly, present critical thinking and problem-solving abilities.

\section{LITERATURE REVIEW}

Hsiao et al. (2017) revealed that the interactivity, integration, and imagination in STEM inquiry method could predict the preference for STEM inquiry method to predict the attitude towards problem-based learning. Ariel and Moffat (2018) discovered that students with the experience in STEM inquiry method outperformed the control group on the understanding of the nature of science and the attitude toward science, but the academic achievement did not appear notable difference. Tamara et al. (2018) proposed that STEM inquiry method could enhance students' learning achievement, satisfaction with course, attitude toward technology, and cooperative learning attitude in the technology practice. Harris and Bruin (2018) regarded STEM education as the most eye-catching teaching approach which simply had students, under the basis of mathematical logic, learn the content through hands-on; with the interdisciplinary teaching structure, students were not restricted to the boundary of a single subject, but cultivated boundary spanning ability under the diverse development. In the hands-on process, making mistakes and failure was the necessary process, as such a process allowed students learning to reflect and continuously make correction, trial, failure, review, and exploration till the success. In this case, students would enhance the patience and frustration tolerance in the learning process and learn to be responsible for themselves. Quigley et al. (2017) indicated that STEM successfully attracted students' learning attitude to have students achieve the active learning ability for lifelong learning and help the knowledge connection. The following hypothesis is therefore proposed in this study.

H1: STEM inquiry method would affect learning attitude.

Lin et al. (2018) mentioned that humans' "creative thinking" was infinite and boundless. The development of "creativity" in fields of art, mathematics, engineering, dance, cooking, literature, agriculture, and science could develop people's imagination with new thinking directions. Shih and Lin (2017) regarded creativity as an item emphasized in modern education; creativity promoted human civilization and enhanced constant progress of technologies that the cultivation of creativity should be started from childhood. Robot was a representative content in STEM education. Kopcha et al. (2017) introduced robot into engineering instruction and considered that it was suitable for the theme of STEM education. Robot teaching presented the advantage that students had to use the scientific and mathematical knowledge and produce mechanism and structure as well as select proper materials and parts to achieve the objective of knowledge and practice. Perignat and KatzBuonincontro (2019) mentioned several basic strategies to cultivate junior high and elementary school students' scientific creativity, including goal orientation, student orientation, class penetration, and faculty optimization. The effect of school education was apparent. Nevertheless, people would face unprecedented problems or solve old problems with new programs in the complicated knowledge society, especially the era with information and technology explosion. The creativity based creative problem-solving ability is necessary. Accordingly, the following hypothesis is proposed in this study.

H2: STEM inquiry method would affect creativity.

Lu et al. (2018) pointed out learning attitude as the key factor in students' learning motivation and learning effectiveness and positive learning attitude as the basis 
of ideal learning; on the contrary, negative or passive learning attitude would seriously affect learning effectiveness. Su and Lin (2018) regarded attitude as the key factor in motivation and learning effectiveness to guide a person's behavior. For this reason, the measurement or change of attitude could predict or change a person's behavior; in other words, the observation and evaluation of learning attitude could predict a person's learning effectiveness and performance in some parts. Bruin and Harris (2017) stated that creativity could be trained through the cultivation with education activities and timely inspiration of creativity to keep pupils' novelty and curiosity about new affairs, cultivate the active problemfinding and problem-solving learning attitudes, and provide students with an open, respectful, positive, and completely accepted environment to positively induce the development of creativity. Machuve and Mkenda (2019) indicated that students learning at schools did not simply absorb knowledge, but learn thinking and meaningful life, e.g., problem solving and creation, solve common problems with cooperative learning attitude, respect and be tolerant, as well as create and apply knowledge to adapt to the rapidly changing times. Consequently, the following hypotheses are proposed in this study.

H3: Learning attitude shows significant and positive effects on knowledge of creativity.

H4: Learning attitude reveals remarkable and positive effects on intention of creativity.

H5: Learning attitude appears notable and positive effects on ability of creativity.

\section{RESEARCH METHOD}

\section{Measurement of Research Variable}

\section{Learning attitude}

Referring to Lu and Ma (2019), learning attitude contains two dimensions in this study.

1. Intrinsic motivation: including learners' personal factors of needs, desire, impulse, affection, and emotion. Intrinsic motivation refers to the motivation to involve in work for acquiring achievement or satisfaction from the value of work.

2. Extrinsic motivation: containing incentives in the environment, objectives, interests, and ambition. Extrinsic motivation refers to the motivation to involve in work for acquiring benefits irrelevant to the value of work (such as reward, appraisal, and order).

\section{Creativity}

Referring to Hong et al. (2019), factors in the development of creativity contain knowledge, intention, and ability.

1. Knowledge: People with creativity would generally present certain professional knowledge. For instance, adequate professional knowledge is required for the creative performance on art; otherwise, creative products would not be generated, and the effect might become worse.

2. Intention: Intention covers personality traits of attitude, tendency, and commitment, which are separated from skills or ability.

3. Ability: Creativity is the cognition ability of humans. The presentation of creativity requires some skills and strategies. According to the opinions and research findings, the generation of creativity requires skills or ability.

\section{Research Object and Sampling Data}

Taking college students in Bangkok, Thailand, as the research object, 316 students are preceded the 16-week (3 hours per week for total 48 hours) experimental research with STEM inquiry method. SPSS is used for analyzing the data, and factor analysis, reliability analysis, regression analysis, and Analysis of Variance are applied to test various hypotheses.

\section{Analysis Method}

Analysis of Variance is utilized in this study for discussing the difference of STEM inquiry method in learning attitude and creativity, and regression analysis is applied to understand the relationship between learning attitude and creativity.

\section{ANALYSIS RESULT}

\section{Reliability and Validity Analysis}

With factor analysis, learning attitude is extracted two factors of "intrinsic motivation" (eigenvalue $=1.983$, $\alpha=0.87$ ) and "extrinsic motivation" (eigenvalue $=1.574$, $\mathrm{a}=0.83$ ) in this study. The cumulative covariance explained reaches $76.251 \%$.

Creativity, through factor analysis, is extracted three factors of "knowledge" (eigenvalue $=3.475, \mathrm{a}=0.88$ ), "intention" (eigenvalue=2.934, a=0.91), and "ability" (eigenvalue $=2.652, a=0.93$ ). The cumulative covariance explained achieves $83.361 \%$. 
Table 1. Difference analysis of STEM inquiry method in learning attitude

\begin{tabular}{|c|c|c|c|c|}
\hline Variable & & $\mathrm{F}$ & $\mathrm{P}$ & Scheffe post hoc \\
\hline STEM inquiry & intrinsic motivation & 24.175 & $0.000^{* *}$ & after education (4.12) > before education (3.73) \\
\hline method & extrinsic motivation & 28.324 & $0.000^{* *}$ & after education (4.04) > before education (3.67) \\
\hline
\end{tabular}

Note: * stands for $\mathrm{p}<0.05$ and ${ }^{* *}$ for $\mathrm{p}<0.01$

Table 2. Difference analysis of STEM inquiry method in creativity

\begin{tabular}{llcll}
\hline Variable & & $\mathrm{F}$ & $\mathrm{P}$ & Scheffe post hoc \\
\hline STEM inquiry & knowledge & 31.447 & $0.000^{* *}$ & after education $(4.23)>$ before education $(3.49)$ \\
method & intention & 29.188 & $0.000^{* *}$ & after education $(4.18)>$ before education $(3.38)$ \\
& ability & 34.352 & $0.000^{* *}$ & after education $(4.41)>$ before education $(3.55)$ \\
\hline
\end{tabular}

Note: * stands for $\mathrm{p}<0.05$ and ${ }^{* *}$ for $\mathrm{p}<0.01$

Table 3. Analysis of learning attitude to creativity

\begin{tabular}{|c|c|c|c|c|c|c|}
\hline \multirow{3}{*}{$\begin{array}{l}\text { dependent variable } \rightarrow \\
\text { Independent variable } \downarrow \\
\text { learning attitude } \\
\end{array}$} & \multicolumn{6}{|c|}{ creativity } \\
\hline & \multicolumn{2}{|c|}{ knowledge } & \multicolumn{2}{|c|}{ intention } & \multicolumn{2}{|c|}{ ability } \\
\hline & $\beta$ & Beta & $\beta$ & Beta & $\beta$ & Beta \\
\hline intrinsic motivation & $2.122 * *$ & 0.206 & $2.092 * *$ & 0.198 & $2.413^{* *}$ & 0.231 \\
\hline extrinsic motivation & $2.247^{* *}$ & 0.215 & $2.168^{* *}$ & 0.209 & $2.337^{* *}$ & 0.224 \\
\hline $\mathrm{F}$ & \multicolumn{2}{|c|}{36.147} & \multicolumn{2}{|c|}{39.289} & \multicolumn{2}{|c|}{43.902} \\
\hline significance & \multicolumn{2}{|c|}{$0.000 * * *$} & \multicolumn{2}{|c|}{$0.000^{* * *}$} & \multicolumn{2}{|c|}{$0.000^{* * *}$} \\
\hline $\mathrm{R} 2$ & \multicolumn{2}{|c|}{0.275} & \multicolumn{2}{|c|}{0.314} & \multicolumn{2}{|c|}{0.369} \\
\hline adjusted R2 & \multicolumn{2}{|c|}{0.253} & \multicolumn{2}{|c|}{0.286} & \multicolumn{2}{|c|}{0.347} \\
\hline
\end{tabular}

Note: * stands for $\mathrm{p}<0.05$ and ** for $\mathrm{p}<0.01$

Data source: self-organized in this study

\section{Effects of STEM Inquiry Method on Learning Attitude and Creativity}

\section{Difference analysis of STEM inquiry method in learning attitude}

Analysis of Variance is applied in this study to discuss the difference of STEM inquiry method in learning attitude, i.e., analysis and explanation before/after STEM inquiry method. Table 1 shows higher intrinsic motivation after STEM inquiry method (4.12) than before STEM inquiry method (3.73), and extrinsic motivation after STEM inquiry method (4.04) is higher than before education (3.67). H1 is therefore supported.

\section{Difference analysis of STEM inquiry method in creativity}

Applying Analysis of Variance to discuss the difference of STEM inquiry method in creativity, before/after STEM inquiry method is analyzed and explained in this study. Table 2 reveals higher knowledge after STEM inquiry method (4.23) than before STEM inquiry method (3.49), higher intention after STEM inquiry method (4.18) than before STEM inquiry method (3.38), and higher ability after STEM inquiry method (4.41) than before STEM inquiry method (3.55). As a result, $\mathrm{H} 2$ is supported.

\section{Correlation Analysis of Learning Attitude and Creativity}

\section{Correlation analysis of learning attitude and knowledge}

To test H3, the analysis results, Table 3, reveal significant and positive effects of intrinsic motivation $\left(\beta=2.122^{* *}\right)$ and extrinsic motivation $\left(\beta=2.247^{* *}\right)$ on knowledge that $\mathrm{H} 3$ is supported.

\section{Correlation analysis of learning attitude and intention}

To test H4, the analysis results, Table 3, show remarkable and positive effects of intrinsic motivation $\left(\beta=2.092^{* *}\right)$ and extrinsic motivation $\left(\beta=2.168^{* *}\right)$ on intention that $\mathrm{H} 4$ is supported.

\section{Correlation analysis of learning attitude and ability}

To test H3, the analysis results, Table 3, reveal notable and positive effects of intrinsic motivation $\left(\beta=2.413^{* *}\right)$ and extrinsic motivation $\left(\beta=2.337^{* *}\right)$ on ability that $\mathrm{H} 5$ is supported.

\section{DISCUSSION}

STEM inquiry method can predict students' creativity. It observes the development of creativity through changes in teaching and the levels of their critical-thinking skills. As aforementioned, creativity is a learning behavior, and creative thinking comprises relatively high skills. Besides, the STEM inquiry method can develop students' positive learning attitudes. This is 
especially meaningful at the moment because of education reform. Many scholars mentioned that it is necessary to help students find interest in their learning materials. An achievement in affective objective can be used as a tool of cognitive learning. Therefore, applying the STEM inquiry method to academic fields could be a teaching method worth promoting. Teachers should encourage students to join the discussions in class and give them more opportunities to speak up. In addition, teachers should also induce students to elucidate the questions or incidents and accept their various opinions and wait for their answers patiently. Teachers should make use of every educational opportunity and bring up some current issues or topics. In this case, students can discuss it with each other and make a point about it. Also, students should develop their critical thinking skills and creative thinking skills in their daily life.

\section{CONCLUSION}

The research findings show that STEM inquiry method instructors could effectively use five thinking stages in each teaching lessons to construct the learning cycle and could have students think of personal uniqueness, fluency, flexibility, and precision at each stage to grasp problems, inference, design \& verification, explanation, and promotion \& development. 1) The utilization of activity in the teaching process allows students connecting past experiences and paying attention to the learning activity and process, i.e., engagement in learning cycle. 2) Allowing students actively operating learning devices, collecting data, and spontaneously exploring problems refers to exploration in learning cycle. 3) Allowing students proposing the understanding of lessons or actually operating the entire process in each lesson, in which instructors could induce scientific concepts in the curriculum, refers to explanation in learning cycle. 4) Instructors could guide students integrating the learned new concepts and skills into personal life with depth, inquiry, and modification to acquire more information and high-level skills, i.e., elaboration in learning cycle. 5) Instructors could timely encourage students and allow students evaluating personal ability; the provision for instructors evaluating personal teaching skills, effectiveness, and goals is evaluation in learning cycle.

\section{SUGGESTION}

According to the research conclusion, the following suggestions are proposed in this study.

1. STEM inquiry method aims to have students cultivate personal scientific activity and inquiry ability through the participation process. For this reason, students should not be limited the ideas in the instruction but should personally experience the entire learning process with guidance. STEM inquiry method means to encourage students' constant inquiry, which is particularly important. In the teaching process, students' central ideas are the important process in each instruction; it is also the teaching core of STEM inquiry method.

2. STEM education, with integrated instruction, cultivates students to learn knowledge and skills and apply to real life. STEM education covers the properties of cross discipline, fun, experience, situation, cooperation, design, practice, technique, and art. During students' learning, the integration of subject knowledge, life experience, and learnercentered should be stressed

3. The characteristics of STEM inquiry method show the course content containing problems in students' life or social issues to combine with students' life experience and induce students' learning interests. In this case, the curriculum design principles of STEM inquiry method could be considered to design curricula with issues in which students are interested or combine a topic or issue with several related fields for integrated teaching. In this case, the teaching time would be abundant, and students could acquire integrated knowledge. Besides, the activities and opportunities for planning self-directed learning could assist students in applying the learned knowledge to solve problems in real life and promote the creative thinking ability.

Author contributions: All authors have sufficiently contributed to the study, and agreed with the results and conclusions.

Funding: No funding source is reported for this study.

Declaration of interest: No conflict of interest is declared by authors.

\section{REFERENCES}

Ariel, R., \& Moffat, S. D. (2018). Age-related similarities and differences in monitoring spatial cognition. Neuropsychology, Development, and Cognition. Section B, Aging, Neuropsychology and Cognition, 25(3), 351377.

https:/ / doi.org/10.1080/13825585.2017.1305086

Bruin, L. R., \& Harris, A. (2017). Fostering creative ecologies in Australasian secondary schools. Australian Journal of Teacher Education, 42(9), 2. https:/ / doi.org/10.14221/ajte.2017v42n9.2

Harris, A., \& Bruin, R. L. (2018). Secondary school creativity, teacher practice and STEAM education: An international study. Journal of Educational Change, 19, 153-179. https://doi.org/10.1007/ s10833-017-9311-2

Hong, J. C., Tsai, C. R., Hsiao, H. S., Chen, P. H., Chu, K. C., Gu, J., \& Sitthiworachart, J. (2019). The effect of the "Prediction-observation-quiz-explanation" inquiry-based e-learning model on flow experience in green energy learning. Computers $\mathcal{E}$ Education, 
133, 127-138. https://doi.org/10.1016/j.compedu. 2019.01.009

Hsiao, H. S., Hong, J. C., Chen, P. H., Lu, C. C., \& Chen, S. Y. (2017). A five-stage prediction-observationexplanation inquiry-based learning model to improve students' learning performance in science courses. Eurasia Journal of Mathematics, Science and Technology Education, 13(7), 3393-3416. https:/ / doi.org/10.12973/ eurasia.2017.00735a

Kopcha, T. J., McGregor, J., Shin, S., Qian, Y., Choi, J., Hill, R., Mativo, J., \& Choi, I. (2017). Developing an integrative STEM curriculum for robotics education through educational design research. Journal of Formative Design in Learning, 1, 31-44. https:// doi.org/10.1007/s41686-017-0005-1

Lin, K. Y., Hsiao, H. S., Williams, P. J., \& Chen, Y. H. (2018). Effects of 6E-oriented STEM practical activities in cultivating middle school students' attitudes toward technology and technological inquiry ability. Research in Science and Echnological Education, 38(1), 1-18. https://doi.org/10.1080/ 02635143.2018 .1561432

Lu, C.-C., \& Ma, S.-Y. (2019). Design STEM course to train STEM literacy of primary students: taking "Animal Mimicry Beast" as an example. Jiaoyu Kexue Yanjiu Qikan, 64(3), 85.

Lu, Q., Shi, V., \& Huang, J. (2018). Who benefit from agency model: A strategic analysis of pricing models in distribution channels of physical books and e-books. European Journal of Operational
Research, 264(3), 1074-1091. https://doi.org/ 10.1016/j.ejor.2017.07.002

Machuve, J., \& Mkenda, E. (2019). Promoting STEM education through sustainable manufacturing: Case study of photovoltaic toys. Procedia Manufacturing, 33, 740-745. https://doi.org/ 10.1016/j.promfg.2019.04.093

Perignat, E., \& Katz-Buonincontro, J. (2019). STEAM in practice and research: An integrative literature review. Thinking Skills and Creativity, 31, 31-43. https:// doi.org/10.1016/j.tsc.2018.10.002

Quigley, C., Herro, D., \& Jamil, F. (2017). Developing a STEM classroom assessment of learning experiences. School Science \& Mathematics, 117(1-2), 1-12. https:/ / doi.org/10.1111/ssm.12201

Shih, T. J., \& Lin, C. Y. (2017). Developing communication strategies for mitigating actions against global warming: Linking framing and a dual processing model. Environmental Communication, 11(6), 840-858. https://doi.org/ 10.1080/17524032.2016.1154886

Su, J. M., \& Lin, T. W. (2018). Building a simulated blockly-Arduino-based programming learning tool: A preliminary study. In 2018 7th International Congress on Advanced Applied Informatics (IIAI-AAI) (pp. 378-381). IEEE. https:// doi.org/10.1109/IIAIAAI.2018.00082

Tamara D. H., Kristin, L., \& David, S. (2018). Making sense of "STEM education" in K-12 contexts. International Journal of STEM Education, 5(32), 1-18. https:// doi.org/10.1186/s40594-018-0127-2

\section{http://www.ejmste.com}

